\title{
An EFL Needs Assessment: Chinese Students at A Canadian University
}

Yilin Sun

This paper analyzes the results of a survey of needs in English, completed by seventy Chinese visiting scholars and graduate students at a Canadian university. It is the first attempt to carry out a needs assessment among Chinese students in Canada by a Chinese. The analysis aims to answer the following questions: 1) What aspects of English do Chinese students think they need most in order to succeed in Canada? 2) Do the perceived needs differ between Chinese visiting scholars and graduate students? 3) Are there significant differences in the needs of individuals in various professional fields? It is hoped that findings from this study will contribute to a more accurate understanding of the language needs of Chinese studying in Canada and to the improvement of English language programs in China and Canada.

\section{INTRODUCTION}

In recent years, since the 'open-door' policy, an increasing number of scholars from the People's Republic of China have been sent abroad for advanced training and research. Although these individuals usually pass English proficiency tests and receive a certain period of cultural orientation and language training before going abroad, they are often shocked to find that they have difficulty understanding what people say to them. (Some may not even understand the lectures in the courses in which they are enrolled; others may not be able to express themselves clearly on their arrival.) The 'culture shock' and language barriers encountered by Chinese students and scholars indicate that what they learned in China does not suffice to ensure their effective participation in real situations in an English-speaking country. In order to know how to narrow this gap between preparatory language studies and actual communication needs, a needs survey can help to identify the aspects of English which Chinese scholars think they may need in order to succeed in an English-speaking setting.

This paper analyses the results of a survey of needs in English completed by seventy Chinese visiting scholars and graduate students at a Canadian university. It is the first attempt to carry out a needs assessment among Chinese students in Canada by a Chinese. The analysis aims to answer the following questions: 1) What aspects of English do Chinese 
students think they need most in order to succeed in Canada? 2) Do the perceived needs differ between Chinese visiting scholars and graduate students? 3) Are there significant differences in the needs of individuals in various professional fields? It is hoped that findings from this study will contribute to a more accurate understanding of the language needs of Chinese studying in Canada and to the improvement of English language programs in China and Canada. ${ }^{1}$

\section{RESEARCH BACKGROUND}

Since Munby's (1978) presentation of a model for the assessment of communication needs there has been considerable discussion of the utility (and drawbacks) of this approach to inform the design of ESL/EFL programs (Holec 1980, Cunningsworth 1983, Coffey 1984). Alternative models have been proposed in Richterich and Chancerel (1980), Mackay and Palmer (1981) and Yalden (1983). Widdowson (1983) has criticized the narrow definitions of language and social functions produced by most needs surveys, suggesting that learning processes should be a more important focus for curriculum design. Stern (1983), among others, has proposed that a wider range of considerations be planned for in language program curricula.

Nevertheless, needs surveys have continued to play an important role in all aspects of educational planning (English and Kaufman 1975, Witkin 1984). For language programs, however, there are few examples, other than Richterich (1983) or Ostler (1980), of the results or applications of surveys of second language needs. A recent evaluation (Burnaby, Cumming and Belfiore 1986) of a Chinese-Canadian cooperative language program has pointed out that empirical data on the actual language needs of Chinese learners in Canada are urgently needed to inform decisions about curriculum development and assessments of language proficiency in China and Canada. Hunter and Keehn (1985), in a recent survey of adult education in China, have stressed the great current needs for applied educational research and data of all kinds to assist China in its modernization plans.

Beatty and Chan (1984) distributed a questionnaire to two groups of Chinese scholars to survey their academic needs. They compared the responses of 24 participants who had not yet left China with those of 22 scholars who had been at a California university for at least six months. The research revealed that although both groups considered they had similar academic needs, the respondents who had been in the U.S. showed more concern that the in-China respondents for the overall importance of almost all the items on the questionnaire. The authors concluded that for curriculum planning, "it is more important to assess the perceived needs 
of those who have experience in the target environment" (1984:58), arguing that those who "have survived initial cultural adaptation" "know what is important for them to learn" (1984:59). No one so far has done any comprehensive study of both the academic and social needs in English of Chinese scholars in Canada. This is the purpose of the present research.

\section{PROCEDURE}

\subsection{Questionnaire}

A questionnaire (see Appendix) was distributed to students from the People's Republic of China studying at one university in a major Canadian city. The questionnaire consisted of the following three parts:

\section{Part A Background Information \\ Part B Assessment of Academic Skills \\ Part C Assessment of Social Skills}

In addition to identifying their age, sex, professional fields in China and Canada and English learning experience, respondents were to rank 15 academic and 15 social skills on a 5-point scale according to the degree of importance to their life and academic study in Canada.

\section{RESULTS}

\subsection{Population Studied}

The population for the present survey consisted of 70 subjects: 37 of them were graduate students (Masters candidates numbered 17, Ph.D. candidates numbered 20); 32 were visiting scholars (including one postdoctoral fellow). There were 54 males and 15 females, ranging in age from 22 to 60 . Among them, $64.3 \%$ were between the age of $22-39 ; 31.4 \%$ were between the age of $40-49$; only $4.3 \%$ were over 50 .

Some of the respondents (15\%) had majored in English at university in China, whereas $85 \%$ had not. Among the participants who had not majored in English at university, about $70 \%$ of them had studied English for 2-5 years on a part-time basis in China; $10 \%$ of them had studied English for less than 2 years; and 20\% studied English for 6 to 7 years. Of the respondents who were English-majors, the average period of English instruction in China was 4 years. The overall average period of full-time English study was 2.2 years. Of all the participants, only 16 had continued their full-time English study in Canada, for periods ranging from 2 months to 12 months. Over $70 \%$ of the total respondents had studied English in Canada on a part-time basis for 8 months or less. Subjects' professional backgrounds in China are listed in Table 1. 
Table 1

Position in China

Number

Percent

University Instructor

25

35.7

Engineer

Graduate Student

7

10.0

16

22.9

Doctor

4

5.7

University English Teacher

6

Manager

BA Student

Professor

Research Associate

2

8.6

2.9

8.6

1.4

4.3

Table 2

Work place in China

Number

Percent

University

47

73.4

Institute

9

14.1

Hospital

1

1.4

4

6.3

Research Institute

3

4.7

Their professional fields at the university in Canada can be classified into three categories: 47 were in Science Programs (including Engineering and Medicine); 11 were in English Programs; and 10 were in Business and Economics programs.

The average number of months the subjects had spent in Canada by the time they completed the questionnaire (in May 1986) was 23 months. ${ }^{2}$ $85 \%$ of them had been in Canada for a period of 2 to 36 months. (See Table 3 for details). None of them had ever worked or studied abroad before.

Table 3

Months in Canada

Position

Visiting scholars

Graduate students

Major

Science

ESL

Business \& Economy

2-24 months 25-36 months $60-78$ months

27

19

\section{2}

0

10 


\subsection{Academic Skills}

\subsubsection{Needs According to Position}

This section of the questionnaire consisted of items representing fifteen academic skills which might be required in the respondents' academic activities. The participants were asked to rate these skills according to the degree of importance, i.e., from 'not at all important' to 'very important' on a five-point scale. Results are classified according to the roles of respondents at the Canadian university, distinguishing between visiting scholars (group A) and degree students (group B).

Table 4 shows, in descending order of importance, the mean total ranking of the perceived needs of group A (visiting scholars). The most important items were understanding instructions of a supervisor and understanding lectures. These responses show a great concern for listening comprehension skills.

Table 4

Perceived Academic Needs from Group A: Visiting Scholars

Ranking Perceived Academic Needs

4.4 understand instructions of a supervisor

4.3 understand lectures

4.1 give talks or seminars

4.1 read books and articles

4.0 use a library

3.9 discuss issues informally with colleagues

3.9 discuss issues in class

3.8 write long reports

3.7 fill out applications and forms

3.6 write short reports

3.6 get information about universities in North America

3.6 take notes in class

3.5 write resumes

3.5 write business letters

2.9 write exams

Also high on the list were a number of items related to research (giving talks or a seminar, using a library) and the skills of reading books and articles. It is apparent that the respondents were highly concerned about their oral skills and receptive skills. Writing skills on the whole were not seen to be as important for this group. Of all the fifteen skills, the lowest in ranking was writing exams. Obviously, this skill is needed more by graduate students than by visiting scholars. 
The relative importance of skills related to listening, speaking and doing research (as well as the corresponding unimportance attached to skills related to study in a classroom for a degree) appear to show that the visiting scholars, on the whole, are research-oriented and are more interested in oral communication and obtaining information.

Table 5 shows the ranking of the perceived needs of group B (graduate students). The predominant concern for academic and research-oriented productive skills - writing long reports (4.4) and giving talks or seminars (4.3) - were seen in this group.

Table 5

Perceived Academic Needs from Group B: Graduate Students

Ranking Perceived Academic Needs

4.4 write long reports

4.3 give talks or seminars

4.2 understand instructions of a supervisor

4.2 understand lectures

4.2 discuss issues in class

4.2 read books and articles

4.2 write exams

4.2 write short reports

3.9 take notes in class

3.9 use a library

3.8 write business letters

3.7 write resumes

3.7 fill out applications and forms

3.6 discuss issues informally with colleagues

3.4 get information about universities in North America

Among the less academic-oriented skills the need for writing business letters ranked highest (3.8). We should notice that the overall importance of almost all the items on the questionnaire is greater in group B than in group A. All academic-oriented productive and receptive skills (listening, speaking, reading and writing) were almost equally emphasized in this group.

In general, both groups indicated they believe that understanding lectures and understanding supervisors were important factors in their successful use of English at the university. Research and academic-oriented skills (giving talks and seminars, reading books and articles, writing long and short reports) were also high in importance for them. The emphasis on the need for knowing how to use a library in both groups indicates that the respondents have realized the important role that a library plays in their research and academic fields. Analysis of Variance showed that there was 
no significant difference on any of the variables except writing exams $(\mathrm{p}<$ 0.01). Spearman Correlations showed that the correlation between the rank orders group A (visiting scholars) and group B (graduate students) was 0.96 .

\subsubsection{Needs According to Professional Field}

If we look at the needs for the rated skills in terms of the respondents' fields at the Canadian university (Table 6), we find that, on the whole, the results are comparable to those in Tables 4 and 5. Analysis of Variance showed that there was no significant difference between ratings on any of the fifteen academic skills $(p<0.01)$. However, Spearman Correlations revealed that there were minor differences among the three different professional fields. The correlation between the rank order group A (English) and group B (Science) was 0.56; between group B and group C (Business and Economics) was 0.40; and between group $\mathrm{A}$ and group $\mathrm{C}$ was 0.54 .

Table 6

Perceived Academic Needs According to Professional Field

$\begin{array}{lccc}\text { Skills } & \text { English } & \text { Science } & \text { Business and Eco } \\ \begin{array}{l}\text { understand instruction } \\ \quad \text { of supervisor }\end{array} & 4.6 & 4.3 & 3.9 \\ \begin{array}{l}\text { understand lectures } \\ \text { discuss in class }\end{array} & 4.6 & 4.1 & 4.5 \\ \text { give talks or seminars } & 4.5 & 3.9 & 4.6 \\ \begin{array}{l}\text { discuss informally } \\ \text { with colleagues }\end{array} & 4.3 & 4.1 & 4.5 \\ \quad \text { read books and articles } & 3.5 & 3.8 & 3.9 \\ \text { take notes in class } & 4.5 & 4.1 & 4.1 \\ \text { write exams } & 4.4 & 3.6 & 4.0 \\ \quad \text { write long reports } & 3.7 & 3.4 & 4.5 \\ \quad \text { write short reports } & 4.1 & 4.1 & 4.8 \\ \text { fill out forms } & 3.5 & 4.1 & 4.2 \\ \quad \text { write resumes } & 3.7 & 3.7 & 3.5 \\ \quad \text { write business letters } & 3.6 & 3.6 & 4.0 \\ \text { get information about } & 3.7 & 3.6 & 4.0 \\ \quad \text { universities in N. America } & 3.2 & 3.6 & 3.7 \\ \text { use a library } & 3.7 & 4.0 & 3.9\end{array}$

The importance of listening comprehension skills was emphasized primarily by respondents studying English. Next, this group saw needs for understanding supervisors and lectures, skills of discussing in class, reading books and articles and giving talks or seminars. The importance of 
taking notes in class was emphasized in this group (4.4) in correspondence to the importance of understanding lectures. For them, writing short reports was not as important as writing long reports (ratings of 3.5 vs. 4.1). Getting information about universities in North America was ranked lowest for all the three groups.

For the Business and Economics majors, the skill of writing long reports was considered exceptionally important (4.8). The importance of classroom-oriented activities such as understanding lectures, discussing subjects in class, giving talks or seminars, taking notes in class and writing exams also ranked very high in this group.

Of all the perceived needs in Table 6, the average mean for each item was well above 3.0. That is to say, the respondents considered all the fifteen skills listed in the section to be important. Priority was given to oral-aural skills and skills that are academic and research oriented.

\subsection{Social Skills}

\subsubsection{Needs According to Position}

The fifteen social skills listed in this section of the questionnaire were ranked in similiar ways by group A (visiting scholars) and group B (graduate students), as shown in Table 7. Spearman Correlations showed that the correlation of the rank orders between groups A and B was 0.86 . Analysis of Variance showed that there was no signigicant difference between ratings on any of the fifteen social skills $(p<0.01)$.

Table 7

Perceived Social Needs According to Position

$\begin{array}{lcc}\text { Skills } & \text { Group A } & \text { Group B } \\ \text { make a phone call } & 4.0 & 4.0 \\ \text { understand radio, film, TV program } & 4.3 & 3.9 \\ \text { read newspapers and magazines } & 4.1 & 3.9 \\ \text { understand culture and customs } & 3.9 & 3.9 \\ \text { conversation with Canadian friends } & 3.7 & 3.8 \\ \text { participate in an informal party } & 3.8 & 3.6 \\ \text { visit a Canadian home } & 3.7 & 3.2 \\ \text { write social letters } & 3.7 & 3.7 \\ \text { use a bank } & 3.7 & 3.6 \\ \text { read ads, catalogues or posters } & 3.6 & 3.6 \\ \text { use public transportation } & 3.3 & 3.5 \\ \text { ask directions } & 3.3 & 3.1 \\ \text { use a mail system } & 3.1 & 3.2 \\ \text { arrange a place to live } & 3.0 & 3.3 \\ \text { shopping } & 2.8 & 2.9\end{array}$


The respondents in both groups indicated the importance of making $a$ phone call; understanding radio, films and TV programs; reading newspapers and magazines; participating in daily conversation with Canadian friends; participating in informal parties; writing social letters; using a bank, public transportation, and mail system; and reading ads, catalogues and posters. One of the noticeable aspects, emphasized equally by both group $\mathrm{A}$ and $\mathrm{B}$, was the strong need for understanding the culture and customs of Canada.

If we look at the responses in terms of an overall percentage, we have a clearer picture of the subjects' attitudes to these activities. By eliminating the missing cases and combining the scale Fairly important, Important and Very important into an Important category, and taking Not at all important as another, the following tabulation emerges:

\section{Table 8}

\section{Skills}

make a phone call

read newspapers and magazines understand culture and customs participate in an informal party conversation with Canadian friends understand radio, film, TV program use a bank

write social letters read ads, catalogues or posters visit a Canadian home use public transportation arrange a place to live use a mail system ask directions shopping
Important Not important

$\begin{array}{ll}91.0 \% & 1.4 \% \\ 91.4 \% & 1.4 \% \\ 90.0 \% & 4.3 \% \\ 88.6 \% & 1.4 \% \\ 87.1 \% & 1.4 \% \\ 87.2 \% & 4.3 \% \\ 85.7 \% & 2.9 \% \\ 82.0 \% & 2.9 \% \\ 82.8 \% & 7.1 \% \\ 81.4 \% & 5.7 \% \\ 75.7 \% & 7.0 \% \\ 71.0 \% & 8.6 \% \\ 70.0 \% & 10.0 \% \\ 65.7 \% & 12.9 \% \\ 65.7 \% & 12.9 \%\end{array}$

Those activities that are culturally-oriented and require more complex strategies for communication, (e.g., making a phone call, reading newspapers and magazines and understanding culture and customs) appeared more important than the remaining activities. This may imply that the respondents are expressing some desire for developing communication competence in order to perform communicative activities. Asking directions and shopping were not considered as important as the rest of the activities. One of the respondents explained the reason as, "It is too simple to do shopping here even without much English." 


\subsubsection{Needs According to Professional Field}

Table 9 contains the mean ranking of the responses from the three major professional groups.

Table 9

Perceived Social Needs According to Professional Field

$\begin{array}{lccc} & & & \begin{array}{c}\text { Business } \\ \text { and }\end{array} \\ \text { Skills } & \text { English } & \text { Science } & \begin{array}{c}\text { Economy } \\ \text { make a phone call }\end{array} \\ \begin{array}{l}\text { understand radio, film, TV } \\ \text { program }\end{array} & 4.5 & 3.9 & 3.5 \\ \text { read newspapers and magazines } & 4.3 & 4.1 & 3.9 \\ \text { understand culture and customs } & 4.4 & 3.9 & 4.1 \\ \text { conversation with Canadian } & & 3.7 & 3.7 \\ \text { friends } & 3.8 & 3.7 & 3.9 \\ \text { participate in an informal party } & 3.7 & 3.6 & 3.8 \\ \text { visit a Canadian home } & 4.2 & 3.2 & 4.0 \\ \text { write social letters } & 4.5 & 3.5 & 3.6 \\ \text { use a bank } & 4.0 & 3.7 & 3.9 \\ \text { read ads, catalogues or posters } & 4.1 & 3.5 & 3.8 \\ \text { use public transportation } & 3.8 & 3.4 & 2.8 \\ \text { ask directions } & 3.7 & 3.1 & 3.0 \\ \text { use a mail system } & 3.7 & 3.1 & 2.9 \\ \text { arrange a place to live } & 3.1 & 3.2 & 3.1 \\ \text { shopping } & 3.3 & 2.8 & 2.6\end{array}$

In general, these responses were very similar to the responses in Table 7. There are not great differences between the three groups. Spearman Correlations showed that the correlation between the rank orders group A (English) and group B (Science) was 0.71 ; between group B and group C (Business and Economy) was 0.60 ; and between group $\mathrm{A}$ and group $\mathrm{C}$ was 0.57 . However, one noticeable difference is the overall importance given to almost all items by respondents who had specialized in English language. It appears that those experienced language learners and users were more concerned (than the non-English majors) with the needs of cultural knowledge, communicative strategies and necessary linguistic knowledge in order to participate in various social activities - e.g., using a bank (4.0), making a phone call (4.5), being a guest in a Canadian home (4.2), and writing social letters (4.5).

Of all the three groups, science students do not seem as 'sociable' as the language and business students. The mean ranking for being a guest in $a$ Canadian home was only 3.2 in the science group, while in the other two groups the means were 4.2 and 4.0 respectively. 
On the whole, the results of this analysis suggest that linguistically complex skills oriented toward communicative strategies, e.g., making $a$ phone call, understanding radio, film, TV programs, and reading newspapers and magazines may be more needed than less demanding survival skills, such as asking directions and shopping. Knowledge of the second culture was regarded as the most important need by respondents studying English. Mass media systems like newspapers, magazines, radio and TV were considered as very important channels for subjects to develop their understanding of the target society and target language.

\section{DISCUSSION AND IMPLICATIONS}

It is now possible to discuss the major questions posed earlier. The first question was What aspects of English do Chinese students think they need most in order to succeed in Canada? The results of this study suggest that all the academic skills in the questionnaire were considered very important, except some tasks requiring skills like writing exams, a skill which is obviously not important for visiting scholars. Most social skills were also considered very important by those respondents. Priority was given to making a phone call, understanding radio, film, TV programs, understanding culture and customs, reading newspapers and magazines, and conversation with Canadian friends.

Along with the suggestions from other findings (Beatty and Chan 1984; Ostler 1980), this writer recommends that the following skills and activities should be emphasized in training programs in China:

\section{Developing Communicative Competence for Academic Needs}

a)ample opportunities for listening to lectures and interviews;

b)writing for science and academic purposes (e.g., writing long and short reports, taking notes from readings and lectures);

c) participating in research-oriented or academic-oriented discussions, both in formal and informal situations of various sorts (e.g., giving talks or seminars; discussing issues with instructors and classmates);

d)skills to obtain and provide information for general academic and research purposes (e.g., using a library ${ }^{3}$; filling out various forms and writing resumes);

e) reading for science and academic purposes (e.g., reading journals and articles; textbooks; and research reports) and general reading strategies.

2. Developing Communicative Competence for the Needs of Social Life

a)ample opportunities for developing oral-aural skills through participating in various authentic or 'authentic-like' activities, such as, 
listening to recordings and the radio; watching TV and video programs from the target country; discussing daily-life activities with native or 'native-like' speakers if possible. ${ }^{4}$

b)ample opportunities to develop knowledge of the second culture was regarded as most important and badly needed by most respondents $(90 \%)$. As one of the respondents stated: "If the English training program is aiming to prepare people who are going to study or work abroad to communicate, I would like to suggest that due attention be paid to introducing the culture, social customs ... of the countries they are going to. In most cases, the failure to communicate successfully is due to the lack of this knowledge."

c) extensive reading skills through reading newspapers, magazines, ads and posters and various forms of text.

One major point is that language training for social skills appears to be considered as important as academic English training. The general language competence of learners may directly influence their abilities to perform academic studies in an English-speaking country. As Hutchinson and Waters (1981:63) put it, "the language of modern technology is a development of Western culture and society ... not an artificial, cultureless code, but an adaptation of the existing resources of the English language and the culture this reflects." Developing general language competence should be considered essential for the success of these learners' academic and scientific studies in Canada.

The second question was Do the perceived needs differ between visiting scholars and graduate students? Analysis of Variance showed that there was no significant difference on any of the variables except writing exams. However, the results from Frequency Tabulations revealed (see Tables 4 and 5) that the visiting scholars were particularly concerned about their oral and receptive skills, while the graduate students paid equal attention to the four academic- and research-oriented language skills (i.e., listening to lectures; writing long and short reports; giving talks or seminars; reading books and using a library).

If we arrange the four language skills according to the degree of importance indicated by both groups, we find visiting scholars gave priority to: listening, speaking, reading and writing. Graduate students gave priority to: writing, listening, speaking and reading. This implies that the respondents identified their needs not only according to their own learning experiences and interests, but also according to the different tasks they were expected to fulfill. Writing exams in English is obviously an integral part of graduate studies, but not necessary for visiting scholars. Second, the graduate students appeared more concerned with an 
overall command of all academic-oriented and research-oriented English skills, especially effective writing skills.

In regards to needs for social skills, Analysis of Variance showed that there was no significant difference on any of the variables. This implies that, overall, both graduate students and visiting scholars expressed similar needs for social uses of English.

The final question in this study was Are there differences in the needs of individuals in various professional fields? Analysis of Variance again showed that there was no significant difference between ratings on any of the fifteen academic skills. The overall means of the three major fields on fifteen items listed in the questionnaire varied from 4.33 to 3.45 . The total average mean was 4.0 . The results indicate that the ability to carry out these fifteen academic activities is important for scholars and students alike. However, Spearman Correlations showed that there were some differences between science students and business students on certain academic skills, like writing long reports and writing exams, which appeared to be extremely important for business students, but not that important for science students. In training programs, therefore, we should consider not only the main objective of developing trainees' communicative competence in performing these diverse activities, but also the trainees' specific needs in each professional field.

The findings from ranking of social need (Table 9) suggested that understanding culture and customs of Canada should be regarded as a key factor to the success of Chinese students' adaptation to social life in Canada. Many respondents indicated that "teaching culture was least emphasized in most language training programs."

To sum up, some of the findings from this study have reinforced what has already been established in previous research. For example, the results show the importance of listening to lectures, giving talks or seminars, and writing for scientific and academic purposes. As in Ostler's (1980) study, the present research exposes the importance of assessing specific language and social needs according to professional fields and positions of the respondents. The study itself adds to the information collected by Beatty and Chan (1984), who proposed that it is important to assess the perceived needs of those who have experience in the target environment, since they clearly provide a better indicator of the actual needs of the student population to be incorporated into curriculum design.

Other findings may stimulate a re-evaluation of some activities commonly taught in EFL or ESL courses, such as shopping, to which respondents gave low priority. An additional value of this assessment is that it enables language educators to predict areas of the curriculum which incoming trainees may be reluctant to accept as important to their future needs as scholars or students in English-speaking settings. The identifica- 
tion of some major-specific and position-specific needs, such as the requirements for graduate students to write research proposals, long reports and examinations; the low priority given to being a guest at a Canadian home by science students, for example, may provide some insights and information to help curriculum design.

It should be noted, however, that the population of this study is limited compared with the overall Chinese population being sent abroad. Findings from this study may not reflect the perceived needs of other populations who are going to study in European countries, or countries other than Canada (Hayhoe 1986). Nevertheless, this needs assessment provides EFL or ESL training programs with valuable empirical data with which to work to supplement teachers' intuitive assumptions about their learners' needs. Since the objective of language training programs in China is to prepare Chinese scholars or students to succeed in Englishspeaking settings, and the purpose of Canadian programs is to continue this aim, assessments of these learners' own perceived requirements are not just useful - they are necessary.

\section{FOOTNOTES}

1. I sincerely thank Prof. Merrill Swain and Alister Cumming for their help and guidance with this study, as well as Dr. Doug Hart and Dr. Muriel Fung for their assistance with statistical analyses.

2. This average length is affected by $10 \mathrm{Ph}$.D. students. They had been in Canada for 60-78 months.

3. In China the library system is less sophisticated compared to the library system in North America.

4. One way to develop both communicative competence and communicative strategies in oral-aural English may be through activities like making phone calls on different topics, since $91 \%$ of the respondents have expressed the strong desire for this.

\section{REFERENCES}

Beatty, C. J. and Chan, J. J. (1984). Chinese scholars abroad: Changes in perceived academic needs. The ESP Journal, 3, 53-59.

Burnaby, B., A. Cumming, and M. Belfiore. (1986). Formative Evaluation Report of the China/Canada Language and Cross-Cultural Program. Toronto: OISE.

Coffey, B. (1984). ESP-English for Specific Purposes. Language Teaching, 17(1), 2-16.

Cunningsworth, A. (1983). Needs analysis - A review of the state of the art. System, II(2), 149-154.

English, F. W and R. A. Kaufman. (1975). Needs Assessment: A Focus for Curriculum Development. Washington, D.C.: Association for Supervision and Curriculum Development.

Hayhoe, R. (1986). A penetration or mutuality? China's educational cooperation with Europe, Japan and North America. Comparative Education Review, 30(4), $532-559$. 
Holec, H. (1980). Learner-centered communicative language teaching: Needs analysis revisited. In The Foreign Language Syllabus and Communicative Approaches to Teaching: Proceedings of a European-American Seminar. Muller (Ed.). Special Issue of Studies in Second-Language Acquisition, 26-33.

Hunter, C. S. J. and M. M. Keehn. (1985). Adult Education in China. London: Croom Helm.

Hutchinson, T. and A. Waters. (1980). Performance and competence in English for specific purposes. Applied Linguistics, 2(1), 56-69.

Mackay, R. and A. Montford. (Eds.). (1978). English for Specific Purposes. London: Longman.

Mackay, R. and J. D. Palmer (Eds.). (1981). Language for Specific Purposes: Program Design and Evaluation. Rowley: Newbury House.

Munby, J. (1978). Communicative Syllabus Design. London: Cambridge University Press.

Ostler, S. E. (1980). A survey of academic needs for advanced ESL. TESOL Quarterly, 14(4), 489-502.

Richterich, R. and J. L. Chancerel. (1980). Identifying the Needs of Adults Learning a Foreign Language. Oxford: Pergamon Press.

Richterich, R. (Ed.). (1983). Case Studies in Identifying Language Needs. Oxford: Pergamon Press.

Stern, H. H. (1983). Toward a multidimensional foreign language curriculum. In Foreign Languages: Key Links in the Chain of Learning. Mead, R. G. (Ed.). Middlebury, VT.: Northeast Conference, 120-46.

Widdowson, H. G. (1983). Learning Purpose and Language Use. Oxford University Press.

Witkin, B. R. (1984). Assessing Needs in Educational And Social Programs. San Francisco: Jossey-Bass Publishers.

Yalden, J. (1983). Communicative Syllabus: Evalution, Design and Implementation. Oxford: Pergamon Press.

\section{THE AUTHOR}

Yilin Sun is a graduate student in the Department of Curriculum and Modern Language Center at the Ontario Institute for Studies in Education. She previously taught EFL at the Wuhan University of Industry in the People's Republic of China. She has been involved in various research projects at OISE.

\section{APPENDIX}

\section{Questionnaire}

This questionnaire is prepared to find out what aspect of English skills people need to study in China before going abroad. The aim of this questionnaire is to collect information which might help English training programs in China. Your participation in this study would be greatly appreciated. Of course, your participation is voluntary. Please do not put your name on the questionnaire. All information collected will be strictly confidential. 
Please bring this questionnaire with you to the meeting on Friday, April 18. If you cannot come that day, please request someone to take it there. Thank you.

There are four parts in the questionnaire. Please answer all the questions in each part. Any comments and suggestions you may have about your English training in China would be greatly appreciated, especially if you think they will help improve the programs and benefit all the people who may study abroad.

If you feel more comfortable making your comments or suggestions in Chinese, please do so.

\section{A. Background}

1. Age

2. Sex

3. Years of English Study in China part time full time

4. Years of English Study in Canada part time full time

5. Your position; professional field and workplace before coming to Canada:

6. Your position, professional field and workplace in Canada: (If you are a student, please list your program and major, eg. M.A. in engineering, Ph.D. in Math, etc.)

7. a) How long have you been in Canada?

b) How long have you been in your present position in Canada?

8. Have you ever studied abroad before? If yes, please name the countries and the period of time below.

\section{Use of English in Canada}

\section{B. Academic Life}


1. Please indicate how important conducting the following activities in English is to your success as a graduate student or a visiting scholar in Canada? (Please use the scale below to indicate your response.)

1. Not at all important

2. Somewhat important

3. Fairly important

4. Important

5. Very important

\section{Spoken Language}

1) understanding instructions

of your supervisor

2) understanding lectures

3) discussing issues in class

4) giving talks or seminars

5) discussing issues informally

with colleagues

$\begin{array}{lllll}1 & 2 & 3 & 4 & 5 \\ 1 & 2 & 3 & 4 & 5 \\ 1 & 2 & 3 & 4 & 5 \\ 1 & 2 & 3 & 4 & 5 \\ 1 & 2 & 3 & 4 & 5\end{array}$

II. Written Language

6) reading books and articles

7) taking notes in class

8) writing exams

9) writing short reports (1-5 pages)

10) writing long reports (5-30 pages)

11) filling out applications and forms

12) writing resumes

13) writing business letters

$\begin{array}{lllll}1 & 2 & 3 & 4 & 5 \\ 1 & 2 & 3 & 4 & 5 \\ 1 & 2 & 3 & 4 & 5 \\ 1 & 2 & 3 & 4 & 5 \\ 1 & 2 & 3 & 4 & 5 \\ 1 & 2 & 3 & 4 & 5 \\ 1 & 2 & 3 & 4 & 5 \\ 1 & 2 & 3 & 4 & 5\end{array}$

III. Obtaining Information

14) getting information about

universities in North America

15) using a library

$\begin{array}{lllll}1 & 2 & 3 & 4 & 5 \\ 1 & 2 & 3 & 4 & 5\end{array}$

2. If there are other academic activities where you use English skills which are not mentioned above, please write them down and indicate how important you think each is. 


\section{Social Life}

1. Please indicate how important you feel conducting the following activities in English is to your social life in Canada? (Please use the scale below to indicate your response.)

1. Not at all important

2. Somewhat important

3. Fairly important

4. Important

5. Very important

1) asking directions

2) shopping

3) using a mail system

4) arranging a place to live

5) using public transportation (e.g. TTC and buses)

6) using a bank

7) making a phone call

8) understanding radio, film and TV programs

9) participating in daily conversation with your Canadian friends

10) participating in an informal party

11) being a guest in a Canadian home

12) reading newspapers and magazines

13) reading ads, catalogues or posters

14) writing social letters

15) understanding culture and customs of Canada

$\begin{array}{lllll}1 & 2 & 3 & 4 & 5 \\ 1 & 2 & 3 & 4 & 5 \\ 1 & 2 & 3 & 4 & 5 \\ 1 & 2 & 3 & 4 & 5 \\ & & & & \\ 1 & 2 & 3 & 4 & 5 \\ 1 & 2 & 3 & 4 & 5 \\ 1 & 2 & 3 & 4 & 5 \\ 1 & 2 & 3 & 4 & 5 \\ & & & & \\ 1 & 2 & 3 & 4 & 5 \\ 1 & 2 & 3 & 4 & 5 \\ 1 & 2 & 3 & 4 & 5 \\ 1 & 2 & 3 & 4 & 5 \\ 1 & 2 & 3 & 4 & 5 \\ 1 & 2 & 3 & 4 & 5 \\ & & & & \\ 1 & 2 & 3 & 4 & 5\end{array}$

2. If there are other academic activities where you use English skills which are not mentioned above, please write them down and indicate how important you think each is. 